\title{
Citierte und zu Rat gezogene Werke.
}

Basnage de Beauval, Eloge de Mr Bayle. („Histoire des Ouvrages des Savants". Dezember 1706.)

Des Maizeaux, La vie de Mr Bayle. Nouvelle édition. La Haye 1732. de Barante, Tableau de la Littérature française au XVIII' siècle. 1809. Sainte-Beure, Du génie critique et de Bayle. ("Revue des deux Mondes", 1. Dezember 1835.)

- Journal et Mémoires de Mathieu Marais. Nouv. Lundis. IX. 1867.

-- Port Royal. Tome V. 5 édition. 189t.

Franck, Ad., Réformateurs et Publicistes. Leipzig 1851.

- Dictionnaire des sciences philosophiques. 1875.

Weiss, Ch., Histoire des Réfugiés protestants de France depuis la Révocation de l'édit de Nantes jusqu'à nos jours. 2 vol. 1853.

Lenient, C., Etude sur Bayle. Paris 1855.

Rigault, H., Histoire de la querelle des Anciens et des Modernes. 1850. IIatin, Histoire politique et littéraire de la Presse en France. 1860.

Sayous, Histoire de la Littérature française à l'étranger. 1861.

Bouillier, F., Histoire de la philosophie cartésienne. 2 vol. 1867.

Aubertin, Clı., L'esprit public au XVI[॰ siècle. Paris 1873.

Deschamp, Arsène, La Genèse du Scepticisme érudit chez Bayle. Liège 1878.

Denis, J., Bayle et Jurieu. Paris 1886.

Nisard, Dés., Histoire de la Littérature française. Tome IV. 13éd. 1886. de Budé, Lettres inédites adressées à J.-A. Turrettini. Paris 1887.

Brunetièrc, F., La critique littéraire au XVIII siècle. Evolution des Genres dans l'Histoire de la Littérature. T'ome I. 1890.

- La critique de Bayle. Etudes de la Littérature française. V• série. 1893.

Gigas, Emile,*) Choix de la Correspontanee inédite de Pierre Bayle (1670-1706). Paris 1890.

*) Ueber diese für die Litteratur- und Kulturgeschichte ungeınein wichtige Publikation vergleiche ${ }_{n}$ Revue critique“, 22. Dez. 1890, pag. $472 \mathrm{ff}$. 
Houssaye, Arsène, La Régence. (Galerie du XVIII siècle, vol. I.) 1890. Texte, Joseph, Jean-Jacques Rousseau et les origines du cosmopolitisme littéraire. 1895.

Rossel, Virgile, Histoire de la Littérature française hors de France. Lausanne 1895.

Janin, Jules, Variétés littéraires. Leipzig s. a.

Tennemann, Geschichte der Philosophie. Bd. XI. Leipzig 1819.

D'Israeli, Curiosities of Litterature. Vol. II. 1835.

Feuerbach, Ludwig, Pierre Bayle nach seinen für die Geschichte der Philosophie und Menschheit interessantesten Momenten dargestellt und gewürdigt. Anspach 1838.

Kurz, H., Geschichte der deutschen Litteratur. Leipzig 1857.

Honegger, Kritische Geschichte der französischen Kultureinflüsse in den letzten Jahrhunderten. Berlin 1875.

Lotheissen, Ferd., Geschichte der französischen Litteratur im XVII. Jahrhundert. Bd. IV. Wien 1884.

Leibniz, Gottfried Wilhelm, Die philosophisehen Schriften von, herausgegeben von C. J. Gerhardt. Bd. III. 1887.

Morf, H., Drei Vorposten der französischen Aufklärung. („Nation“ 1891, No. 41-42.)

Hettner, H., Literaturgeschichte des XVIII. Jahrhunderts. - Geschichte der fran\%ösischen Literatur in XVIII. Jahrhundert. 5. Auflage, bes. von H. Morf. 1894. 